Session 1754

\title{
Description and Assessment of a Business Plan Competition and New Venture Fair at San José State University
}

\author{
By Malu Roldan, Ph.D., Asbjorn Osland, Ph.D., Michael Solt, D.B.A., \& Burton \\ V. Dean, Ph.D. \\ College of Business, San Jose State University
}

\begin{abstract}
After the first business plan competition, in May 2003, San José State University (SJSU) faculty and community entrepreneurs serving on the university's Silicon Valley Center for Entrepreneurship (SVCE) concluded that the process should be spread over an academic year. Hence, the New Venture Fair (NVF) was born, which was held Dec. 16, 2003. The feedback from all sources has been very positive regarding the NVF. A significant NVF exhibit was the Hewlett Packard Mobile Computing Grant (HPMCG). All teams completed projects that were impressive to most observers from the university and greater community but additional lessons were learned that will be important to subsequent comparable projects, as well as next year's NVF.
\end{abstract}

During 2003 a team of faculty from the Colleges of Engineering, Humanities and the Arts, and Business at SJSU and also several entrepreneurs from Silicon Valley focused on new venture creation by students. First, we'll briefly summarize our experience with the SJSU Silicon Valley Business Plan Competition (SVBPC) that took place in spring 2003. But the bulk of this paper will focus on the NVF held on December 16, 2003. The two are intertwined in that one of the primary lessons learned from the SVBPC was that students needed more than one semester to ramp up from the ideation stage to a completed business plan. The Dec. 16, 2003 NVF was to foster more ideas for the June 2004 SVBPC. One key to the success of the NVF was the involvement of student teams that were part of the HPMCG. The HPMCG used crossdisciplinary Entrepreneurial Teams (E-Teams) to develop mobile computing applications. SJSU began using E-Teams in its first SVBPC. E-Teams are promoted by the National Collegiate Inventors and Innovators Alliance [1] and are composed of students engaged in innovation from various colleges within the university.

The SVBPC, including the NVF, process is in part modeled after the University of Pennsylvania's Wharton Business Plan Competition [2]. Wharton divides the process into three phases and a culminating event called the Venture Fair. Phase I is for idea generation and in Phase II the teams provide more detail in a business overview that focuses on issues that must be addressed before the business plan is developed. The best 25 Phase II teams then progress to 
Phase III where they present a business plan. At SJSU we chose to conduct the SVBPC in two phases: an ideation stage in the fall 2003 semester culminating in the NVF and the SVBPC the following semester in June 2004 [3)].

The remainder of the paper is organized as follows: descriptions of the 2003 BPC, NVF, and HPMCG are provided; then a brief summary evaluation of the NVF participants and attendees will be presented, as well as of the students involved in the HPMCG; and, finally, lessons learned from the NVF and the HPMCG will be discussed.

\section{SVBPC spring 2003 [4]}

The SVBPC was organized into four rounds: Proposed Venture Concepts, Marketing and Competitive Analyses, Financial Plans, and Complete Business Plans. Feedback was given to each submission for each round. During each round, faculty and external mentors worked with the student E-Teams. Our objective was to empower business, engineering, industrial design, and computer science students with the entrepreneurial skills to start businesses. A completed business plan was the main deliverable from the E-Teams process, with new venture creation the goal for the best plans.

Cross-functional and virtual teams are a well-studied phenomenon [5, 6, 7]. Research also suggests that interdisciplinary product development experiences provide strong preparation and relevant background for students about to enter the workforce [8]. Our E-Team-SVBPC process benefited from the recommendations of these researchers.

In part due to the popularity and necessity of using cross-functional teams in industry, various academic accrediting bodies require teamwork, including engineering [9]. Numerous examples of teamwork in engineering education can be found $[10,11,12,13,14,15]$. The importance of teamwork is also true for SJSU's Industrial Design that participated in E-Teams [16] as well as business $[17,18]$.

Groups have been used in higher education for decades. As early as 1963, Dean [19] discussed groups as an educational tool in an operations research graduate program. Anwar and Rothwell [20] reported on the importance of team-based collaborative problem solving in an engineering technology class and they concluded that the focus on team process dramatically improved the students' ability to work and problem solve in teams. Colbeck, Campbell and Bjorklund [21] studied the implementation process and reported additional concerns such as the importance of factors such as: faculty guidance, students converging on a common goal, and managing diversity-related conflict. The authors concluded that group projects should be employed throughout the curriculum.

Coordination at SJSU proved a challenge. Using Dean's Project Management course as a structural coordinating mechanism worked well. Dean teaches a method he calls project management of innovative startup firms (PMIS) [22]. He demonstrates that eight basic tasks exist in every startup, and that applying the Critical Path Method to the activities in these tasks, along with corresponding precedence relations and activity durations, yields status reports on the startup firm, as well information that is useful in the startup's business plan. During spring 2003, PMIS was applied in 13 E-Teams and in three startup firms in Silicon Valley. 
The 2003 SVBPC was the output of the E-Team process. Student teams competed internally in three rounds. All the final round judges in the E-Society's 2003 SVBPC were active in entrepreneurship practice. The 2003 winners were Mohamed Aslam Ali and Ilya Ronnin, both recent SJSU MBA graduates, who received incubator space at the Environmental Business Cluster and the Software Business Cluster, respectively. Mohamed's business plan was focused on converting used automobile tires to activated carbon to be used in water filters. He also won the eight-state business plan competition held in conjunction with the Minority Business Development Agency Youth Symposium on August 9, 2003 in Oakland, California. Mohamed reportedly has obtained a formal commitment for $\$ 5$ million of the $\$ 6$ million required to complete the project. Ilya and his partners developed a $\$ 30,000$ software-driven add-on for machine tool lathes to do the work of computerized machine tools that cost \$1 million or more new. However, they later abandoned the business as used equipment sold on E-Bay was reportedly too competitive for them to continue.

The following major university business plan competitions have tracked the number of companies created since 1996; they are as follows with the number of new ventures in parentheses: University of Texas at Austin (20), University of Arizona (15), University of Oregon (6), University of Chicago (5), and the University of Georgia (3) [23]. With an output of one promising new venture, the first SJSU SVBPC was successful.

In May 2003 we asked the E-Teams for feedback through a process roughly comparable to a course evaluation to see if the process was leading toward the goal of new venture creation through effective business plan development. The challenges cited led faculty to conclude that the process be spread over an academic year. Hence, the NVF idea was born, which concluded with a campus-wide event held Dec. 16, 2003.

\section{The New Venture Fair}

The NVF was formed as the kick-off event for the SVBPC to showcase innovation produced by SJSU students and faculty and to strengthen the connections between SJSU and the Silicon Valley entrepreneurship community. The NVF was envisioned as having "booths" (really tables) set up by exhibitors that would be perused by an audience that would stroll through the NVF and enjoy refreshments; COMDEX (http://www.comdex.com/ ) served as a model. The exhibits featured internal SJSU student and faculty innovations and external Silicon Valley start-up innovations. The first-ever NVF was held at SJSU on December 16, 2003.

The NVF organizers had to create the infrastructure for an event unlike anything that SJSU had undertaken before and organize everything by December 16, 2003. The NVF became a sevenday-per-week activity for the organizers. The NVF was operated very much like a start-up, with all of the ups and downs that start-ups face.

Many logistical issues had to be handled: venue, parking, catering, volunteer staff, media coverage, room set-up, audio-visual equipment, prizes, gift coupons, and securing a keynote speaker. The event was held on the SJSU campus. Keynote speaker U.S. Congresswoman Zoe Lofgren, representing San Jose, personally visited each exhibit at the NVF. 
Web pages were key parts of the infrastructure that had to be put into place early in the process. The web page was the main vehicle by which the organizers informed students, faculty, startups, service providers, sponsors, and the general public about the NVF.

Funding for the NVF was secured from the Silicon Valley Bank Foundation, Hummer Winblad Venture Partners, TechStock Ventures, the Silicon Valley Center for International Trade and Development, Fernandez \& Associates LLP, and Fenwick \& West LLP. Start-up companies who had exhibits at the NVF paid a small fee to help cover the expenses of the NVF. All of the NVF expenses were covered and a small surplus was generated that will be used to cover future SVBPC expenses. C\&J Engineer of Hollister, California, donated a motorized scooter that became the Grand Door Prize, and Microsoft Corporation donated six Xboxes that were given to each member of the team that won the Elevator Pitch Contest. Two local restaurants donated coupons that were given to the registrants as they entered the NVF.

The biggest challenges facing the organizers were to assure participation in the NVF by SJSU students and faculty teams, Silicon Valley start-ups, and service providing organizations, and to attract an audience of SJSU students and faculty, Silicon Valley investors, angels and venture capitalists, and the general public. For SJSU participation, top down and bottom up approaches were used. The organizers spoke at a Provosts' Deans Council meeting, at the University Chairs meeting, and at a College of Science Chairs meeting. Emails were sent directly to faculty members, a flyer was put in every faculty mailbox on campus, and flyers were distributed outside the Student Union and posted in classrooms across campus. Email messages were sent to SJSU alumni and the event was posted in the University Calendar of Events. An article about the NVF appeared in the campus newspaper two weeks before the NVF.

The event was also announced outside the SJSU campus. Software Developer Forum, the Silicon Valley Association of Start-Up Entrepreneurs, and the International Angel Investors sent emails to their constituencies; well over 5,000 email messages were sent. San Jose is home to eleven business incubators and these were contacted directly.

Arranging for the exhibits of the innovations and new venture concepts was a major task. A list of over 100 start-ups from the local incubators was constructed. Many faculty members in Biology, Business, Engineering, Environmental Sciences, Industrial Design and Hospitality Management were contacted directly about having student and/or faculty exhibits at the NVF. The organizers also worked with the DeAnza Community College Entrepreneur Boot Camp to have exhibits by its students. However, the largest set of internal exhibitors was from the HPMCG, as nine of the ten HPMCG teams exhibited their projects at the NVF. The faculty involved in this project (i.e., Solt, Roldan, and Engineering Professors Xiao Su and Weider Yu) were supportive of the NVF throughout the fall semester, and this led to the high level of participation by these teams. Notably, the Elevator Pitch Contest was won by the HPMCG team that was developing a wireless Tablet PC application for managing housekeeping activities at the Hotel Valencia in San Jose's Santana Row, a new, up-scale shopping area.

The NVF included 16 exhibits by students and faculty. Nine were student teams that had developed mobile computing applications as part of the HPMCG, four were by SJSU College of Engineering faculty and students, and one was by a SJSU student who wanted to start a 
Louisiana Bayou restaurant chain. Also, two exhibits were from the DeAnza Community College Entrepreneurship Boot Camp. Twenty-three startup companies from local incubators and five service providing organizations set up exhibits at the NVF, including the two winners from the Silicon Valley Center for Entrepreneurship's 2003 Business Plan Competition. SJSU's Career Planning \& Placement office, Masters in Biotechnology program, and Entrepreneurial Society student club also set up tables. Approximately 240 people attended the NVF. In the next section we describe the HPMCG, which provided the resources and support for nine of exhibits.

\section{HP Mobile Computing Grant E-teams [24]}

The HPMCG funded an E-Team project that charged cross-functional teams of students with the task of developing mobile computing applications for local clients and entrepreneurs. The project brought together courses from Management Information Systems, Finance, and Computer Engineering. True to the University's metropolitan mission, the project participants sought to leverage the resources available in the greater Silicon Valley area to enrich the project learning environment.

The project grew out of a \$230,000 Applied Mobile Technology Solutions in Learning Environments grant from Hewlett Packard. The grant included equipment, installation, and student support which, along with a \$50,000 matching grant from SJSU's Provost's office, provided mobile equipment to participating faculty, allowed for loans of devices to students for a semester, and supported the creation and staffing of a lab that would serve as the center of activity for the classes in the project. In the same timeframe, Microsoft Corporation was launching its next generation server (Windows Server 2003) and developer products (Visual Studio .Net 2003) that incorporated the company's core platform for the development of applications for mobile devices (the Compact .Net Platform). Through participation in the Microsoft Developer Network Academic Alliance, the various departments involved were able to obtain the training, software, and support to build the computing platform to support the HPMCG student teams' development work. Lastly, Solt, a finance professor and grant director, arranged to have San Jose's SDForum (i.e., Software Development Forum) provide students in the classes with free student memberships. These memberships not only gave students access to the SDForum user groups and events but also made them eligible to pitch their ideas in several showcases that the forum organizes to give information technology start-ups exposure to the local venture capitalist community.

The faculty team sought to identify motivating and challenging real-world mobile computing projects for the student teams. Projects were targeted to specific devices - either a TabletPC or a PocketPC PDA. Every member of each student team was provided with the device that matched the requirements of the project that his/her team was working on. The three departments' Microsoft Developer Network Academic Alliance subscriptions provided students with free developer (Visual Studio .Net 2003) and server software (Windows Server 2003, SQL Server 2000) for their use in course related work.

Student teams were required to develop a business plan and a working prototype of a mobile application solution to a problem or need posed by their clients. Finance students had the primary task of developing the financial analysis for the business plan while computer engineering $(\mathrm{CmpE})$ students had the primary task of developing the prototype. Because of their grounding in 
both technology and business matters, MIS students were given the task of coordinating the team's efforts and acting as bridges to aid communication among the team members and balance out the team's skills. All students were expected to collaborate on the design of the prototype and writing the business plan.

At the end of the semester, each student team presented its work to its client in a private meeting. Additionally, all teams presented their work in a general session attended by all students in the mobility classes and a local community panel. The teams' projects were also presented in several Microsoft Sponsored sessions in ICIS2003, a leading MIS conference, including a preconference technology education showcase, and theatre and kiosk presentations at the Microsoft booth in the exhibit hall. Lastly, nine of the ten HPMCG teams participated in the NVF. Students in all HPMCG classes were given incentives to participate in the NVF. Incentives included strong promotion of NVF awards and prizes, exposure for HPMCG students, and the inclusion of NVF participation in course requirements.

\section{A. Technology Platform}

The Hewlett Packard Applied Mobile Technology Solutions in Learning Environments grant funded two servers, 48 Compaq TC1000 Tablet PCs, 42 Hewlett Packard Ipaq 5450s, 23 laptops, two servers, printers, projectors, relevant peripherals, and funds for extending the university's wireless network to several classrooms in the business and engineering buildings. Participating professors were provided Tablet PCs and Ipaqs to help them get familiar with the technologies and their capabilities. As preparation for teaching the classes, Microsoft provided free hands-on training programs on the Visual Studio, Net 2003 platform.

The HP grant also included support for two student teaching assistants. These students were assigned the task of setting up equipment in the mobile computing lab, assisting faculty and students with technology and development issues, and tracking the inventory of devices. Two servers were established for the project. One server was used as a developer server, sitting within the university firewall and providing an insulated space for student teams to test out their prototypes. The other server was set up to be the production server for the project - housing the project web site, student team web sites, and, eventually, summaries of the work done by the teams. (This server can be accessed at http://hp.sjsu.edu.)

\section{B. Class Goals and Structure}

The HPMCG project had the following goals:

Provide students with a cross-functional team experience. While cross-functional teams are widely used in industry, students in universities tend to develop a discipline-specific view of the concepts they learn that puts them at a disadvantage when going out into industry and being asked to work in a cross-functional mode. Additionally, while cross-functional teams can produce exceptional results, they are also very difficult to manage and participate in. The HPMCG project provided students with a guided cross-functional experience so that they could experience the issues and benefits of collaborating in a team that integrates a diversity of perspectives and skills. 
Provide students with challenging and motivating real-world projects. To motivate students and provide them with a realistic experience, we sought projects that would truly stretch their abilities and would bring the teams in contact with local organizations that students considered trendy and "cool."

Provide students with hands-on experience in the use and implementation of leading edge mobile technologies. The HPMCG project provided students with devices for the duration of a semester to give them the opportunity to fully integrate their Tablet PCs or PDAs into their lives. The aim was to help students build a strong understanding of the capabilities and challenges of the mobility technologies, and how they might be marketed to various target customers.

Increase students' familiarity with local technology and entrepreneurial resources. The HPMCG classes closely integrated resources in the local community with classroom activities. This outreach provided a motivating set of projects, access to technology and software, and access and exposure to local entrepreneurs and other potential investors.

The courses were structured in the following manner:

Linked three courses offered separately in MIS, CmpE, and Finance. Each department involved in the project offered its own mobility course: Business 118S - Mobile Computing Strategy in MIS; CmpE 189 -- Special Topics in Mobile Software Design and Implementation in CmpE; and Business 179B - Financial Analysis for New Ventures in Finance. These courses were offered as electives, open to junior and senior level students in each department. Several graduate students in $\mathrm{CmpE}$ also joined the teams via independent study courses. There were a total of four professors involved in teaching the mobility classes - one each from MIS and Finance, and two from $\mathrm{CmpE}$ who team-taught the $\mathrm{CmpE} 189$ class and supervised the work of the $\mathrm{CmpE}$ graduate students. The professors teaching each course coordinated material across courses and encouraged students to participate fully in their teams. Each of the four faculty members also took on the role of faculty manager for at least two mobility teams, providing coaching and guidance with team dynamics and client interaction.

Joint courses to form teams, match up with clients, and present prototypes. The HPMCG project faculty scheduled several joint meetings bringing together students from all three classes. For fall semester 2003, joint meetings were used to form student teams, to have student teams and clients meet each other and match up, to have a training session on tablet pc development, and to present two preliminary and one final version of each team's prototype and business plan.

Each team required to develop a business plan and build a prototype of the mobile application it proposes. Ten teams with approximately six members each were formed from the students enrolled in the HPMCG courses. Most teams were composed of two members from each department involved - MIS, CmpE, and Finance. Teams were required to develop a business plan for a mobility application prototype that they were developing for a problem posed by their client. The required business plan had a traditional structure and early on provided students in all classes with a detailed outline of the business plan along with specific assignments for team members - based on the knowledge and capabilities students were supposed to possess as a result of the training they had received in earlier courses in their respective departments. While

Proceedings of the 2004 American Society for Engineering Education Annual Conference \& Exposition Copyright (C) 2004, American Society for Engineering Education 
the intent was to have students from all three departments collaborate on the conception and writing of the business plan document, the business students from Finance and MIS were expected to take on the bulk of the business plan analysis and writing.

The second team requirement was development of a prototype of a mobility application to address the need raised by its client. MIS students were expected to take the lead in designing the application and the infrastructure required to implement a production level system. They were expected to collaborate closely with their teammates - especially, the CmpE students - to bring the design to fruition using the technologies provided to them in their respective courses.

\section{Team Projects}

Teams were assigned to projects during a joint session among all courses. Since two of the clients had two teams working on their projects, there were a total of eight clients working with the ten student teams on the following projects:

1. Hotel Valencia proposed a project to transform their system for tracking housekeeping and maintenance work from a paper-based one to a real-time, mobile, wirelessly connected system. They were assigned two teams: one to develop a TabletPC solution and the other to develop a PocketPC solution.

2. Camera Cinemas proposed a project to integrate handheld devices into the movie viewing experience - via chat sessions, concession stand orders, etc. Two teams were assigned to this project, both developing PocketPC solutions.

3. McGraw-Hill proposed a project to explore enhancements to their e-book offerings through the application of TabletPC technologies. One team was assigned the task of developing such enhancements from a student's perspective.

4. The Chair of the MIS department proposed the development of a grading application that leveraged the inking capabilities of the Tablet PC to ease professors' efforts at grading student assignments. One team was assigned this task.

5. The University's Parking Services Department was interested in exploring a solution to the university's parking crunch via an improved system for distributing information on space availability in various university parking lots. One team was assigned to work on this project for the Pocket PC platform.

6. A local entrepreneur, Paseman, proposed the development of an online clearinghouse on the various events happening at any given time in the San Francisco Bay Area. His interest was eventually building an online resource to help individuals make decisions about which of the multitude of events to attend. One team was assigned to work on this project for the TabletPC platform.

7. A CmpE professor, $\mathrm{Yu}$, proposed the development of a student information system that would allow students to access university information and student records via handheld devices. One team was assigned to work on this project for the Pocket PC platform.

8. An entrepreneur proposed an extension to an enhancement he had made to the ebook model. He had developed an application for annotating e-books then saving these annotations as an XML file that could be used as an overlay for other instances of the same e-book. One team was assigned to work on this project for the Tablet PC platform.

\section{Evaluation and Assessment}




\section{A. Evaluating the NVF}

Based on comments recorded by the participants and visitors, future planners of the NVF should consider suggestions such as the following:

1. The organizing team needs to be flexible and understanding in addition to being well organized

2. The NVF principals should have a designated project office to facilitate coordination and communication; effective communication is crucial.

3. Attract more $\mathrm{VC}$ and angel investor participation and service providers (e.g., law firms, accounting firms, etc.).

4. Provide a catalog with complete contact numbers/emails and more information about the exhibitors.

5. Send out maps and provide more signs to give directions to event hall.

6. Booths would be better than tables and the booths should have better visual aids.

7. Consider rotating the location (e.g., convention center).

8. More advertising on campus and off would make more people aware of the NVF.

9. Invite more CEOs to participate and speak.

In sum, the NVF exceeded the expectations of its organizers and the consensus of registrants and exhibitors was that it was useful and informative.

\section{B. Evaluating the HPMCG}

To assess the learning outcomes and guide future design for this novel class design, we administered several questionnaires throughout the semester, including:

1. A pre-test with items on student demographics, confidence with various skills involved in completing course requirements, civic engagement, technology knowledge, and expected use of mobile devices.

2. A pre-test on course and team expectations.

3. Peer review questionnaires administered twice over the semester assessed each students' perspective on how well he/she was performing on his/her team, how well his/her teammates were performing, and how well the team itself was performing. 4. A post-test with items on confidence with various skills involved in completing course requirements, technology knowledge, and expected use of mobile devices.

5. A post-test on course and team expectations.

Fifty three students completed the pre-test and 43 completed the post-test. The questionnaire items and a chart summarizing our findings from questionnaires 1 and 4 are provided in Figure 1. While preliminary, these results suggest that the cross-functional collaborative nature of the HPMCG classes helped students achieve the overall learning goals that we established for each of the specific courses - paralleling the roles that each team member played in his/her team. MIS and Finance students tended to gain the greatest confidence in their understanding of mobile technologies and their application in specific business settings (Items 1-4). The MIS and CmpE students reported the greatest gains in their confidence with the integration of mobile computing into their everyday lives (Items $7 \& 8$ ). The MIS students reported the greatest gains in confidence with two skills associated with project management - delivering the project on time and presenting the team's work in a professional manner (Items $9 \& 10$ ). 
Figure 1

Questionnaire Items and Chart of Changes between Pre- and Post-tests on Course-Specific Skills

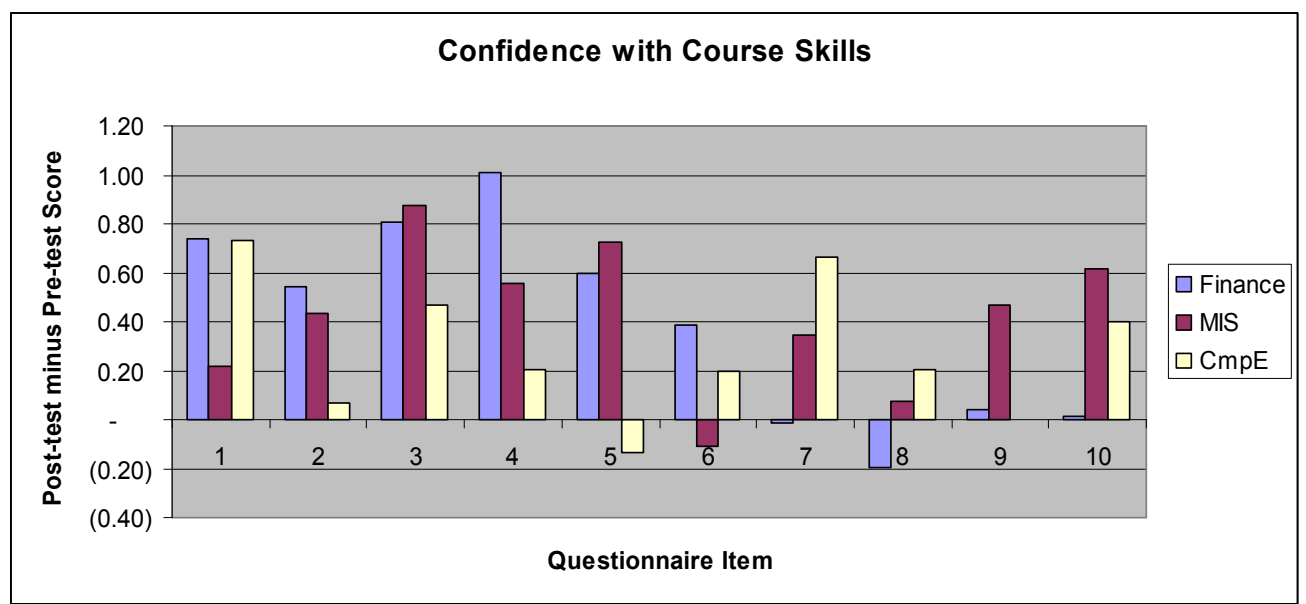

1. I am confident that I can conduct access and assess the quality of materials necessary to conduct research on mobile technologies, industries and companies.

2. I am confident that I can conduct a thorough assessment of mobile technology's development and future prospects.

3. I am confident that I can conduct a thorough analysis of the application of mobile technologies in a specific business or non-profit organization.

4. I am confident that I can work with a team to develop a prototype of a mobile technology application that meets the requirements of a business or non-profit client. 5. I am confident that I can work with a team to analyze the feasibility of a mobile technology application.

6. I am confident that I can work with a team to assess the costs and benefits of deploying or commercializing a mobile computing application.

7. I am confident that I can quickly learn and integrate mobile computing tools into my daily activities - in and out of school.

8. I am confident that I can quickly learn and integrate mobile computing tools to coordinate meetings and activities with my teammates.

9. I am confident that I can work with a team to develop a mobile computing prototype and business case in a professional manner and deliver it on time.

10. I am confident that I can work with a team to present a mobile computing prototype and recommendations to a business audience in a concise, clear and professional manner.

\section{Lessons Learned}

\section{A. From the NVF}

For a first effort, the NVF was very successful. The feedback from all sources has been very positive. Since the infrastructure for the event has been built, future NVFs should be even better. Also, repeat performances should be enhanced as the NVF's reputation grows throughout the region. Still, there are many lessons that have been learned from the initial efforts: 
Earlier involvement by support structure. Students from Dean's project management class were brought in to help manage some of the growing number of tasks surrounding the NVF, but they began their efforts late in the Fall Semester, and to get the full benefit of their efforts, these students need to be brought in much earlier in the process.

Timing of the NVF. The NVF was held during Final Exam week, and getting the attention of students and faculty during this time was challenging. This date was selected so that the NVF could be held simultaneously with the Department of Industrial Design's student-project exhibition and because the number of student exhibitions would be maximized by holding an event at the end of the semester when class projects would be finished. Future NVFs will likely be held at a different time.

Strengthening the connection to Silicon Valley. A "chicken and egg" situation exists for the startup companies and investors: neither group will commit to coming without knowing that the group has committed. In October, the International Angel Investors agreed to hold its December meeting on the SJSU campus at the conclusion of the NVF, and this was important in getting the attention of the start-up companies. However, the process of locking in the start-ups took longer than expected, so the necessary information about which start-ups would be exhibiting at the NVF was not transmitted early enough to the angel group for them to get a large number of their members to attend, and this was probably compounded by having the NVF so close to the holidays. More timely execution of getting start-ups and investors involved can solve this problem.

\section{B. From the HPMCG}

As with all first attempts at a new class structure, the HPMCG team's first semester with the eteam structure was quite challenging - although not without its successes. Despite difficulties and through much effort, all teams completed projects that were impressive to most observers from the university and greater community, including attendees of the NVF, ICIS2003, and the final joint meeting in December. On average, clients gave teams a score of 9.2, out of a possible 10 points, when asked to rate the overall performance of the team. Below is a summary of some of the lessons and challenges to be addressed by the team in the second semester of the project:

Need to define MIS students' role more explicitly as that of project management. As the bridge between their business and technology teammates, MIS students play a role that is continually shifting and somewhat undefined. This is a very difficult position for an undergraduate to handle. To address this difficulty, students will be provided with more material on project management in the early part of the semester. MIS students will also be explicitly assigned to take on the role of project managers on their teams. To encourage team participation, all professors will be asked to include a team participation requirement as part of their grading schemes.

Aim to match classroom experiences more closely with field experiences. HPMCG students responded best to classroom situations that captured the applied and motivating nature of their real-world experiences with clients and their teams. Classroom experiences will be structured to minimize lecturing and have students working in breakout groups and then reporting on their analyses to the entire class. To this end, students will be encouraged to use their devices to 
support the research and analyses that the teams do in class. Additionally, students' experiences in the field will be used as case studies for class discussion.

Use formative evaluation extensively. Given the high levels of uncertainty in a project based class, where expectations from many constituents have to be balanced and creativity encouraged, conscious use of formative evaluation is useful for reducing ambiguity regarding student team goals and class requirements over the course of the semester. As teams presented their prototypes, faculty members give them feedback on how close they are to the final class requirements - giving teams guidance on how to best match expectations and temper their creativity. Rather than receiving one final summative score on their work for the semester, teams are provided with interim scores that allow them to assess how well they are meeting course goals. The teams are then provided the opportunity to improve on these interim scores in future presentations of their work.

Set student expectations not only regarding course goals but also regarding uncertainty levels. Lastly, given that most of their undergraduate classes are highly structured, students tend to get frustrated with the high levels of uncertainty inherent in problem based courses such as those in the HPMCG project. While this can be and will be addresses by the HPMCG team via an increase in course structure, it will also be necessary to point out that the uncertainty is a key element of life and work and essential to bringing an element of reality to such courses. Providing a setting where students can experience and work through their reactions to such uncertainty can help students develop valuable skills to take into the workplace, particularly in these times of high uncertainty and change in the business world and in the information technology industry.

1. Source (5/15/03): www.nciia.org.

2 Source (1/10/04): http://www.whartonbpc.com/participants/phasei.html.

3 For details, go to the web pages: http://www.cob.sjsu.edu/SVBPC/ and http://www.cob.sjsu.edu/NVF/.

4 This section is based on a paper entitled "Lessons learned in first business plan competition at San Jose State University" (by Dean, B., Osland, A. \& Solt, M.) that has been accepted for a special issue of the International Journal of Engineering Education entitled "The Entrepreneurial Engineer: Educating Tomorrow's Innovator," edited by John Feland.

5 Legare, T. "How Hewlett-Packard Used Virtual Cross-Functional Teams to Deliver Healthcare Industry Solutions" Journal of Organizaional Excellence, Autumn 2001; DeSanctis, G, Wright, M, and Jiang, L. "Building a Global Learning Community" Communications of the ACM, December 2001; Kock, N. "Managing with Web-based IT in mind" Communications of the ACM, May 2002; Clark, M., Amudson, S. and Candy, R. "Cross-Functional Team Decision-Making and Learning Outcomes: A qualitative illustration" Journal of Business and Management, Summer 2002.

6 Sethi, R., Smith, D., Park, C. “How to Kill a Team’s Creativity,” Harvard Business Review, August 2002.

$7 \mathrm{http}: / /$ productdevelopment.com

8 Darian, J. and Coopersmith, L. "Integrated Marketing and Operations Team Projects: Learning the Importance of Cross-functional Cooperation" Journal of Marketing Education, August 2001; Rothsteing, P. "When Worlds Collide: Integrated Development with Business and Design Students" Design Management Journal, Summer 2002.

9. Accreditation Board of Engineering and Technology, Criteria for Accrediting Engineering Programs, 1 (2002), www.abet.org.

10. J. M. Feland, Building Teammates: Bringing Better Team Skills to Design Courses, Proceedings of the American Society for Engineering Education Annual Conference (2002).

11. J. M. Feland and C. Fisher, Cramming Twenty Pounds More into a Sophomore Design Tool Kit: Increasing Curricular Loads on Design Students and Enjoying It!, The American Society of Mechanical Engineers. The Proceedings of the ASME International Mechanical Engineering Congress and Exposition, and ASME Curriculum Innovation Award Honorable Mention (2002). 
12. C. S. McMahon and J. P. Lavelle, Implementation of cross-disciplinary teams of business and engineering students for quality improvement projects, Journal of Education for Business, 73, 150-157 (1998).

13. S. Anwar and W. J. Rothwell, Implementing team-based collaborative problem solving in ET: A case study, Journal of Engineering Technology 14, 34-38 (1997).

14. T. Kiely, Innovation congregations, Technology Review 97, 54-61 (1997).

15. R. Wilson and T. Costlow, Rethinking education, with an emphasis on teams, Electronic Engineering Times 1050, 130-138 (1999).

16. National Association of Schools of Art and Design Handbook, (2002).

17. Source (8/27/03): http://www.aacsb.edu/accreditation/brc/standards-4-25.pdf, p. 52.

18 Source (8/27/03): http://www.aacsb.edu/accreditation/brc/standards-4-25.pdf , p. 53.

19. B. V. Dean, Group research as an educational tool, Proceedings of the 3rd International Conference on Operational Research, 471-489 (1963).

20. S. Anwar and W. J. Rothwell Implementing team-based collaborative problem solving in ET: A case study, Journal of Engineering Technology 14, 34-38 (1997).

21. C. L. Colbeck, S. E Campbell, and S. A. Bjorklund, "Grouping in the dark: What college students learn from group projects," The Journal of Higher Education 71, 60-83 (2000).

22. B. V. Dean, The project management approach in the "systematic management" of innovative startup firms, Journal of Business Venturing 1, 149-160 (1986).

23 Ballon, M. "MIT springboard send Internet company aloft.” Inc. 20, no. 18 (December 1998).

24 This section is based on a paper accepted by NCIIA for presentation at its March 2004 conference (San Jose, CA). The paper is entitled "Fostering Creativity and Collaboration via Cross-Functional Education" by Malu Roldan, Assistant Professor, Management Information Systems; Michael Solt, Professor of Finance; and Xiao Su, Assistant Professor, Computer Engineering, all of San Jose State University.

Authors' biographies:

\section{BURTON DEAN}

Dr. Burton Dean is the Founding Director of SJSU's SVCE. He is Professor of Organization \& Management where he has served since 1985. He was previously Department Chair. His research interests include entrepreneurship, strategic management, operations management, and project management. He is the author of six books, more than 30 chapters and 100 papers and is listed in more than 30 biographies.

\section{ASBJORN OSLAND}

Dr. Asbjorn Osland is an associate professor of Organization \& Management and served on the SVCE steering committee. He has published refereed articles and cases dealing with international management and entrepreneurship. He worked for eleven years in Third World development in Latin America and West Africa. He also served as the HR manager for Chiquita in Panama.

\section{MALU ROLDAN}

Dr. Malu Roldan is with the faculty of San Jose State University's Management Information Systems Department. She has published refereed articles on electronic commerce, business education, and service learning. In 2003-2004, she coordinated a project, funded by a Hewlett Packard, on the application of mobile computing in established and entrepreneurial organizations.

\section{MICHAEL E. SOLT}

Dr. Michael Solt is Professor of Finance and a member of the SVCE Steering Committee. Dr. Solt has published extensively in refereed and professional journals. Dr. Solt is professionally active in the Silicon Valley community. He was selected as the College of Business Outstanding Undergraduate Instructor in 1995 and a University Teacher Scholar in 2000. 